\title{
Optimization of Vegetable Oil-Based Biodiesels by Multi-Response Surface Methodology (MRS) using Desirability Functions
}

\author{
A. O. Mustapha ${ }^{1 *}$, R.A. Adepoju ${ }^{2}$ and Y. T. Afolabi ${ }^{3}$ \\ ${ }^{1,2}$ Department of Chemical, Geological \& Physical Sciences, Faculty of Pure and Applied Sciences. \\ Kwara State University Malete, PMB 1530, Ilorin, Kwara State, Nigeria. \\ ${ }^{3}$ Department of Physical Sciences, Industrial Chemisty Programme, Landmark University, \\ PMB 1001, Omu Aran, Kwara State, Nigeria \\ *Correspondents Author: aliru.mustapha@kwasu.edu.ng, +2348111020181. \\ Received 02 August 2020; accepted 19 August 2020, published online 28 August 2020
}

\begin{abstract}
Environmental concerns associated with petroleum resources have propelled the development of sustainable and renewable alternatives to petroleum based products. Vegetable oil is one amongst the foremost abundant bio-based feedstocks. The interest in using vegetable oils and low molecular weight alcohols by direct transesterification have shown great potential as alternatives to petroleumbased diesel, and the production of bio-based diesel continues to increase. Utilization of multiresponse surface methodology (MRS) for the most effective combination effect or response from the uses of input to output variables to optimize the yield and higher heating values (HHV) of biodiesels was investigated. In this work, utilizing variety of non-edible vegetable oils like castor (Ricinus communis L), jatropha (Jatropha curcas), and neem (Azadirachta indica) seeds and several process variables or inputs, including mixing time, mixing speed, process temperature and catalyst dosage to formulate high quality renewable fuels were further explored. The outputs were yield, viscosity, higher heating value, density and turbidity. The proposed optimization scenarios for biodiesel using the statistical (MRS) models was aimed to optimize the processes to achieved high conversion and higher heating values, while reducing the reaction time, turbidity, density, and viscosity in the samples. The results showed catalyst dosage as the most important variable for all the three samples. For maximum yield of $100 \%$, the molar ratio of 6.25 , catalyst of $0.75 \mathrm{wt} . \%$, reaction speed of 499.99 $\mathrm{rpm}$, reaction time of $19.88 \mathrm{~min}$ and temperature of $24.50{ }^{\circ} \mathrm{C}$ were found as optimal conditions; while the molar ratio of 5.60, catalyst of $1.01 \mathrm{wt} . \%$, the reaction speed of $499.5 \mathrm{rpm}$, reaction time of 20.00 min and temperature of $35.50{ }^{\circ} \mathrm{C}$ were optimal conditions for maximum biodiesel yield.
\end{abstract}

Keywords: biodiesel yields, optimization, statistical model, catalyst dosage.

\section{Introduction}

The environmental concerns associated with petroleum resources have propelled the development of sustainable and renewable alternatives to petroleum-based products. One of the renewable raw materials that have been widely used in chemical industries is vegetable oil; others are sugar, starch, and cellulose. Vegetable oils and low molecular weight alcohols have shown great potential as alternatives to petroleum-based diesel, and the interest in using them to produce bio-based diesel continues to increase. Vegetable oil is one amongst the foremost abundant bio-based feedstocks. Vegetable oils are utilized in numerous bio-based applications because of their important practicality, low toxicity, accessibility, biodegradability and low cost. A molecule of vegetable oil, known as a triglyceride, has three fatty acid chains connected to a glycerol chain. There are various forms of fatty acid within and among different triglyceride molecules [1]. Biofuels (biodiesel, bioethanol, biogas etc) are terribly enticing choices to overcome the energy crisis since waste feedstocks are obtainable freely for biofuels using different chemical and biological conversion technologies. The biodiesel production, which may be used as a mix or blend with diesel oil is increasing globally, which can grow in the coming years because of continuous dwindling of fuel reserves.

Recently, the worldwide crude costs are setting a record high within history because of heavy dependence on crude as a significant supply of fuel for transportation and electricity generation. On the opposite hand, the 
exploitation of these standard energy resources is an additional reason for worldwide warming, which has to be tackled by adopting alternative energy sources. Biodiesel production from waste cooking oil (WCO) and non-edible indigenous seed oils is an attractive option, but the high free fatty acids (FFA) content in waste oils are severe bottlenecks for the trans-esterification.

The WCO oil will be processed to sophisticated refined cooking oil (RCO) to provide refined biodiesel (RBD), that is way more cost-effective than eatable edible fat, and may be a favourable different alternative to edible fat and oil [2]. Spent oil and fats cause substantial discarding issues in several countries of the world, whereas biodiesel is created from fats and oils either biochemically or with chemicals. There are generally four ways that oils and fats can be remodeled into biodiesel. Amongst these, transesterification is the best typically used method because it decreases the viscosity of the oil [3].

The use of a statistical method of MultiResponse Surface Methodology (MRS) to model and maximize production processes can be adopted. Experimental designs for yield optimization require the design of experiments (DoE) that must be established using Response Surface Methodology (RSM) with design inputs to measure the outputs or response as shown in Figure 1: Design of Experimental Variables [4].

\section{Theoretical Framework}

Experimental designs for yield the planning of experiments (DoE) that has got to be established using RSM with design inputs to measure the outputs or response as shown in Figure 1

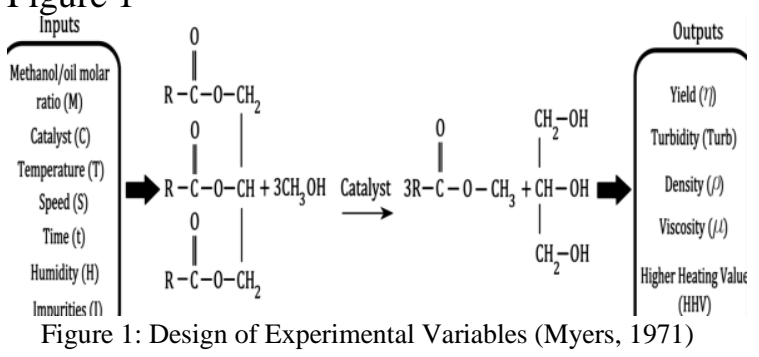

Optimization of biodiesel variables using Response Surface Methodology

Atapour et al [5] optimized biodiesel production using alkali-catalyzed transesterification of used cooking oil. Optimization of esterification of mixed oil with a high proportion of free fattyacid was similarly investigated [6, 7] showed the application of response surface methodology for optimization of biodiesel production by transesterification of vegetable oil with alcohol. Optimization of biodiesel production from the waste vegetable oil exploitation response surface methodology, response surface optimization of associate degree in transesterification of waste vegetable oil and used transesterification of neat and used cooking oil in the optimization for biodiesel production and response surface methodology as associate tools for optimized biodiesel production using rice bran and flower oils were reported by many authors [8 -13]. Using response surface methodology for the optimization and conversion of vegetable oils like castor (Ricinus communis L), jatropha (Jatropha curcas), and neem (Azadirachta indica) to biodiesel production has not been reported.

In this work, optimization and conversion of castor, jathropha and neem using oil/methanol molar ratio, reaction temperature, catalyst, speed and reaction time to generate a statistical model that can predict their conversion to biodiesel are now investigated.

\section{Materials and Methods}

\subsection{Materials and Chemicals}

Castor (Ricinus communis L), jatropha (Jatropha curcas), and neem(Azadirachta indica) seeds were purchased from Mandate Market, Ilorin, Kwara State, Nigeria. Methanol with a purity of $99.5 \%$ and Potassium Hydroxide $(\mathrm{KOH})$ were purchased from Sigma Aldrich Company. Apparatus were supplied by Sigma Aldrich (Gillingham Dorset, UK). Biodiesel analyses were administered using separating funnel, micro-pipette, reflux set, digital hot plate/magnetic stirrer, thermostated water-bath, pycnometer (ASTM D941), pH meter (Hanna HI 4212 model), CannonFenske viscometer Ostwald (Cannon Instrument Co., State College, PA, USA) and bomb calorimeter (Parr-1351 from Parr Instrument Company, Moline, IL, USA).

2.2 Biodiesel production

Refining and pretreatment processes of 100 $\mathrm{mL}$ of crude oils started with the removing impurities before economical transesterification and to bring the free fatty acid (FFA) levels to below $0.5 \%$. Trans- 
esterification processes were followed with the mixture of oils and methanol at the pre-set molar ratio, reaction temperature, reaction time, reaction speed heated and $\mathrm{NaOH}$ as dosage catalyst.

\subsection{Response Surface Method (RSM) for} Optimizing Biodiesel

RSM methodology seeks to establish the relationships between input variables (i.e. independent variables) and one amongst variables (i.e., response variables) for waste cooking oils [14]. RSM was developed originally by Box and Wilson [15] to model experimental processes. However it has been used with different techniques to optimize industrial processes and products [16, 17].. RSM consists of a group of statistical techniques that use a regression model that depends on a low-degree polynomial function. The development side of the $R$ package appearance for a combination of essential factors that satisfies the strategy criteria of every response and [14, 18].

\section{Experiments Design}

Optimization model using RSM: The DoE input variables to be used are: time $(\mathrm{t})$, speed $(\mathrm{S})$, catalyst $(\mathrm{C})$, temperature $(\mathrm{T})$, and oil/ methanol molar ratio $(\mathrm{M})$, The three factors and three levels of a Box-Behnken Design (BBD) would be adopted [14]. The experimental factors and their ranges for optimization are: reaction time $(30-60)$, reaction speed (400-800 rpm), reaction $\mathrm{NaOH}$ catalyst (1-2 wt. \%), reaction temperature (40 $\left.-60^{\circ} \mathrm{C}\right)$, and waste cooking oil/ methanol molar ratio $(6: 1-9: 1)$. The expected measurable outputs are: yield, turbidity, density, viscosity, and higher heating value (HHV). Table 1 contains the variable ranges to cover the intervals popularly used in the literature.

Table 1: Experimental design levels with independent variables using the Box-Behnken Design (BBD) method

\begin{tabular}{llllll}
\hline Inputs & Notation & \multicolumn{2}{c}{ Magnitude } & Levels \\
\hline & & & -1 & 0 & +1 \\
\cline { 3 - 6 } Time & $\mathrm{T}$ & Min & 30 & 45 & 60 \\
Speed & $\mathrm{S}$ & Rpm & 400 & 600 & 800 \\
Temp & $\mathrm{T}$ & ${ }^{\circ} \mathrm{C}$ & 40 & 50 & 60 \\
Catalyst & $\mathrm{C}$ & wt. $\%$ & 1.0 & 1.5 & 2.0 \\
Molar & $\mathrm{m}$ & wt. $\%$ & $6: 1$ & $7.5: 1$ & $9: 1$ \\
ratio & & & & & \\
\hline
\end{tabular}

Table 1 shows the inputs at various levels and combinations by applying the statistical software operating conditions from the from the planning matrix [14]. During this work, 45 experiments were accustomed to generate combination possibilities to determine the optimal conversion of biodiesel. Table 2 shows the design matrix of the transesterification of the three non-edible seed oils using combination variables of speed, time, temperature, catalyst and molar ratio for the experiments.

Table 2: The transesterification of non-edible seeds oils design matrix

\begin{tabular}{llllll}
\hline \multirow{2}{*}{ Sample } & \multicolumn{5}{c}{ Inputs } \\
\cline { 2 - 6 } & $\begin{array}{l}\text { Molar } \\
\text { Ratio }\end{array}$ & $\begin{array}{l}\text { Catalyst } \\
(\text { wt. } \%)\end{array}$ & $\begin{array}{l}\text { Time } \\
(\min )\end{array}$ & $\begin{array}{l}\text { Speed } \\
(\mathrm{rpm})\end{array}$ & $\begin{array}{l}\text { Temp } \\
\left({ }^{\mathrm{O}} \mathrm{C}\right)\end{array}$ \\
\hline $\mathrm{N}_{6: 1}$ & $6: 1$ & 1 & 30 & 400 & 40 \\
$\mathrm{~J}_{6: 1}$ & $6: 1$ & 1 & 30 & 400 & 40 \\
$\mathrm{C}_{6: 1}$ & $6: 1$ & 1 & 30 & 400 & 40 \\
$\mathrm{~N}_{7.5: 1}$ & $7.5: 1$ & 1.5 & 45 & 600 & 50 \\
$\mathrm{~J}_{7.5: 1}$ & $7.5: 1$ & 1.5 & 45 & 600 & 50 \\
$\mathrm{C}_{7.5: 1}$ & $7.5: 1$ & 1.5 & 45 & 600 & 50 \\
$\mathrm{~N}_{9: 1}$ & $9: 1$ & 2 & 60 & 800 & 60 \\
$\mathrm{~J}_{9: 1}$ & $9: 1$ & 2 & 60 & 800 & 60 \\
$\mathrm{C}_{9: 1}$ & $9: 1$ & 2 & 60 & 800 & 60 \\
\hline
\end{tabular}

After phase separation in each experiment, the biodiesel yield was calculated from the ultimate. Additionally, density ( $\rho$ ), higher heating value (HHV), viscosity $(\mu)$ and turbidity (Turb) were similarly analysed in keeping with ASTM D6751-09 Quality Evaluations [19, 20]

\section{Results and Discussions \\ 4.1 Experimental Results}

The physical properties of the biodiesels which were produced in the optimum conditions were measured and presented in Table 3 for yield ( $y$ ), density $(\rho)$, higher heating value (HHV), viscosity $(\mu)$ and turbidity (Turb) analyses. 
Table 3: Experimental results obtained for the output variables ( $n$, Turb, $\rho, \mu$, and HHV), according to the Box-Behnken DoE Design Matrix (Table 2).

\begin{tabular}{|c|c|c|c|c|c|c|}
\hline \multicolumn{6}{|c|}{ Outputs } & mean square error (RMSE) are determined \\
\hline Sample & $\begin{array}{l}\text { Yield } \\
\%(\mathrm{n})\end{array}$ & $\begin{array}{l}\text { Turb } \\
\text { (NTU) }\end{array}$ & $\begin{array}{l}\text { Density } \\
\rho(\mathrm{g} / \mathrm{mL})\end{array}$ & $\begin{array}{l}\text { Viscosity } \\
\mu\left(\mathrm{mm}^{2} / \mathrm{s}\right)\end{array}$ & SG & KinsimgoictheH\$akmples in Table 4 for the capacity \\
\hline $\mathrm{N}_{6: 1}$ & 53.8 & $38.5 \pm 0.07$ & 3.69 & $32.2 \pm 0.14$ & 0.97 & odeis as uiscussed (ivianna $e t$ \\
\hline $\mathrm{J}_{6: 1}$ & 29.5 & $119.50 \pm 0.7$ & 6.09 & $14.60 \pm 0.14$ & 0.96 & 8.46., 20174)4.14Table 10 shows \\
\hline $\mathrm{C}_{6: 1}$ & 55.5 & $19.50 \pm 0.7$ & 3.52 & $52.0 \pm 0.00$ & 0.97 & 1erłors as 43 pininimum errors correspond to $\mathbf{\eta}$ \\
\hline $\mathrm{N}_{7.5: 1}$ & 50 & $77.5 \pm 0.7$ & 3.87 & $31.2 \pm 0.00$ & 0.96 & 8.04 $\mathrm{AAE}$ equią to 9.337 and RMSE equal to \\
\hline $\mathrm{J}_{7.5: 1}$ & $\begin{array}{l}84 \\
411\end{array}$ & $\begin{array}{l}91 \pm 1.41 \\
68.5+0.7\end{array}$ & $\begin{array}{l}1.89 \\
4.50\end{array}$ & $\begin{array}{l}14.65 \pm 0.07 \\
52.1+0.00\end{array}$ & $\begin{array}{l}0.94 \\
0.98\end{array}$ & $1156.706)$, and 3 the minimum error correspond to \\
\hline $\mathrm{N}_{9: 1}$ & 58 & $73 \pm 0.00$ & 3.43 & $32.90 \pm 0.14$ & 0.96 & 5. - $^{1}$ (MAE $4 \&$ equal to 0.009 and RMSE equal to \\
\hline $\mathrm{J}_{9: 1}$ & 87 & $77.5 \pm 0.7$ & 1.04 & $14.95 \pm 0.07$ & 0.94 & 142012 \\
\hline $\mathrm{C}_{9: 1}$ & 91.1 & $83.5 \pm 0.7$ & 2.39 & $51.85 \pm 0.07$ & 0.93 & $21.6912) \cdot \quad 43.54$ \\
\hline
\end{tabular}

\subsection{Analysis of variance}

These equations show the second-order polynomial functions and combinations of input variables that were obtained to model yield, Turbidity, density, viscosity, and HHV [14]

$\eta=2217+0.8937 . \mathrm{M}-12.79 . \mathrm{A} 2-3.572 . \mathrm{M} . \mathrm{C}-$

2163.C2- 2.689.T-0.01284.Q2 + 2.860.H + 0.05896.C.H

(1)

Turb $=2565-1.43 \cdot \mathrm{M}^{3}+2.2 \cdot \mathrm{A}^{2}-0.23 \mathrm{M} \cdot \mathrm{C}$ 2508. $\mathrm{C}^{2}-0.60 . \mathrm{T}$

Density $=63.9-0.0990 . \mathrm{M}^{3}+0.00065 . \mathrm{M}+$ 0.0251.M.C - 57.6.C C $^{2}$ 0.0155.T

Viscosity $=-1561+1.85 \cdot \mathrm{M}^{3}-0.047 \cdot \mathrm{M}+17 \cdot 7 \cdot \mathrm{A}^{2}$ $+1471 . \mathrm{C}^{2}+1.61 . \mathrm{T}$

Specific gravity $=1.0566-0.001118 . \mathrm{M}^{3}-0.000108$

.M - 0.00841. $\mathrm{A}^{2}+$ 0.000304.M.C- 0.000492.T (5)

$\mathrm{HHV}=426-0.258 . \mathrm{M}^{3}-0.022 . \mathrm{M}-1.92 . \mathrm{A}^{2}+$

0.283.M.C - 419.C ${ }^{2}$
Tables of ANOVA results for each of the final quadratic models are given in Tables $4-8$. The $p$-value is less than 0.05 for most variables and is statistically significant for each quadratic model. The regression model provided the multiple correlation coefficients $\left(R^{2}\right)$ as a measure of variation of the mean and is close to 1 indicating the predictive capability of these models is excellent.

Table 4: Analysis of Variance (ANOVA) Table for the " $\boldsymbol{\eta}$ " quadratic model

\begin{tabular}{cccccc}
\hline Source & $\begin{array}{c}\text { Degree of } \\
\text { freedom }\end{array}$ & $\begin{array}{c}\text { Sum of Square } \\
\text { (Adj) }\end{array}$ & $\begin{array}{c}\text { Mean } \\
\text { Square } \\
(\mathbf{A d j})\end{array}$ & F Value & P-Value \\
\hline $\mathbf{K}$ & 5 & 3670.34 & 734.067 & 53.83 & 0.004 \\
$\mathbf{M}$ & 1 & 2.34 & 2.343 & 0.17 & 0.706 \\
$\mathbf{A}^{2}$ & 1 & 304.26 & 304.261 & 22.31 & 0.018 \\
$\mathbf{M} \times \mathbf{C}$ & 1 & 31.61 & 31.606 & 2.32 & 0.225 \\
$\mathbf{C}^{\mathbf{2}}$ & 1 & 137.08 & 137.082 & 10.05 & 0.050 \\
$\mathbf{T}$ & 1 & 2.07 & 2.070 & 0.15 & 0.723 \\
$\mathbf{E r r o r}^{\mathbf{2}}$ & 3 & 40.91 & 13.638 & & \\
$\mathbf{R}^{\mathbf{T}}$ & 8 & 3711.25 & &
\end{tabular}


Table 5: Analysis of Variance (ANOVA) table for the "Turb" quadratic model

\begin{tabular}{|c|c|c|c|c|c|}
\hline Source & $\begin{array}{l}\text { Degree of } \\
\text { freedom }\end{array}$ & $\begin{array}{l}\text { Sum of Square } \\
(A \mathbf{A} \mathbf{j})\end{array}$ & $\begin{array}{c}\text { Mean } \\
\text { Square } \\
\text { (Adj) }\end{array}$ & F Value & P-Value \\
\hline$K$ & 5 & 5159.03 & 1031.81 & 2.01 & 0.301 \\
\hline $\mathbf{M}^{3}$ & 1 & 88.33 & 88.33 & 0.17 & 0.706 \\
\hline$A^{2}$ & 1 & 2.24 & 2.24 & 0.00 & 0.952 \\
\hline$M \times C$ & 1 & 16.84 & 16.84 & 0.03 & 0.868 \\
\hline$C^{2}$ & 1 & 573.10 & 573.10 & 1.11 & 0.369 \\
\hline$T$ & 1 & 20.50 & 20.50 & 0.04 & 0.855 \\
\hline Error & 3 & 1542.69 & 514.23 & & \\
\hline$R^{2}$ & 8 & 6701.72 & & & \\
\hline
\end{tabular}

Table 6: Analysis of Variance (ANOVA) table for the "p" quadratic model

\begin{tabular}{cccccc}
\hline Source & $\begin{array}{c}\text { Degree of } \\
\text { freed om }\end{array}$ & $\begin{array}{c}\text { Sum of Square } \\
\text { (Adj) }\end{array}$ & $\begin{array}{c}\text { Mean } \\
\text { Square } \\
(\mathbf{A d j})\end{array}$ & F Value & P-Value \\
\hline $\boldsymbol{K}$ & 5 & 17.1774 & 3.43549 & 22.64 & 0.014 \\
$\mathbf{M}^{3}$ & 1 & 3.3849 & 3.38494 & 22.31 & 0.018 \\
$\boldsymbol{M}$ & 1 & 0.0007 & 0.00066 & 0.00 & 0.952 \\
$\boldsymbol{M} \times \boldsymbol{C}$ & 1 & 0.3635 & 0.36351 & 2.40 & 0.219 \\
$\boldsymbol{C}^{2}$ & 1 & 0.4285 & 0.42850 & 2.82 & 0.191 \\
$\boldsymbol{T}$ & 1 & 0.0140 & 0.01397 & 0.09 & 0.781 \\
Error $^{2}$ & 3 & 0.4552 & 0.15172 & & \\
$\boldsymbol{R}^{2}$ & 8 & 17.6326 & & \\
\hline
\end{tabular}

Table 7: Analysis of Variance (ANOVA) table for the " $\boldsymbol{\mu}$ " quadratic model

\begin{tabular}{cccccc}
\hline Source & $\begin{array}{c}\text { Degree of } \\
\text { freedom }\end{array}$ & $\begin{array}{c}\text { Sum of Square } \\
\text { (Adj) }\end{array}$ & $\begin{array}{c}\text { Mean } \\
\text { Square } \\
\text { (Adj) }\end{array}$ & F Value & P-Value \\
\hline$K$ & 5 & 1764.67 & 352.934 & 3.29 & 0.178 \\
$\mathrm{M}^{3}$ & 1 & 248.29 & 248.285 & 2.32 & 0.225 \\
$M$ & 1 & 3.51 & 3.509 & 0.03 & 0.868 \\
$A^{2}$ & 1 & 256.69 & 256.687 & 2.40 & 0.219 \\
$C^{2}$ & 1 & 260.07 & 260.069 & 2.43 & 0.217 \\
$T$ & 1 & 268.83 & 268.834 & 2.51 & 0.211 \\
Error & 3 & 321.40 & 107.135 & & \\
$R^{2}$ & 8 & 2086.07 & & \\
\hline \multicolumn{5}{c}{ Significance code: 0.05} \\
\hline
\end{tabular}

Table 8: Analysis of Variance (ANOVA) table for the "HHV" quadratic model

\begin{tabular}{cccccc}
\hline Source & $\begin{array}{c}\text { Degree of } \\
\text { freedom }\end{array}$ & $\begin{array}{c}\text { Sum of Square } \\
\text { (Adj) }\end{array}$ & $\begin{array}{c}\text { Mean } \\
\text { Square } \\
\text { (Adj) }\end{array}$ & F Value & P-Value \\
\hline$K$ & 5 & 154.570 & 30.9139 & 1.64 & 0.363 \\
$\mathrm{M}^{3}$ & 1 & 2.860 & 2.8596 & 0.15 & 0.723 \\
$M$ & 1 & 0.751 & 0.7508 & 0.04 & 0.855 \\
$A^{2}$ & 1 & 1.735 & 1.7350 & 0.09 & 0.781 \\
\hline
\end{tabular}




\begin{tabular}{cccccc}
\hline$M \times C$ & 1 & 47.269 & 47.2690 & 2.51 & 0.211 \\
$C^{2}$ & 1 & 14.666 & 14.6664 & 0.78 & 0.443 \\
Error & 3 & 56.512 & 18.8375 & & \\
$R^{2}$ & 8 & 211.082 & \\
\hline
\end{tabular}

Table 9: Predicted error process critical for yield, turb, density, viscosity, HHV, using quadratic models.

\begin{tabular}{llllll}
\hline ERROR & $\eta$ & Turb & $\rho(\mathrm{g} / \mathrm{mL})$ & $\mu$ & HHV \\
\hline MAE & 9.337 & 5.00 & 0.090 & 0.998 & 0.310 \\
RMSE & 11.706 & 8.622 & 0.012 & 1.450 & 0.398 \\
\hline
\end{tabular}

Figure 2 shows the link between the experimental values that were obtained (Table 1) and also the predicted (quadratic models) values of $\eta$ (Figure 2a), Turb (Figure 2b), $\rho$ (Figure 2c), $\mu$ (Figure 2d), and HHV (Figure 2e). The figures show that these models suffice for the prediction of these values, because the residuals that were obtained were small and also the correlations between actual and predicted values were high [14].

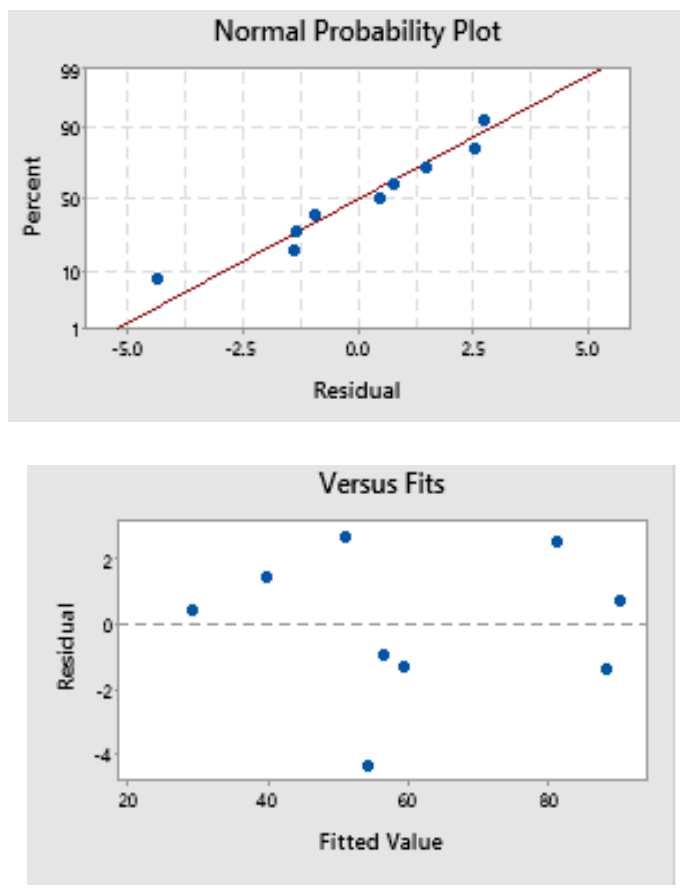

(a) Yield
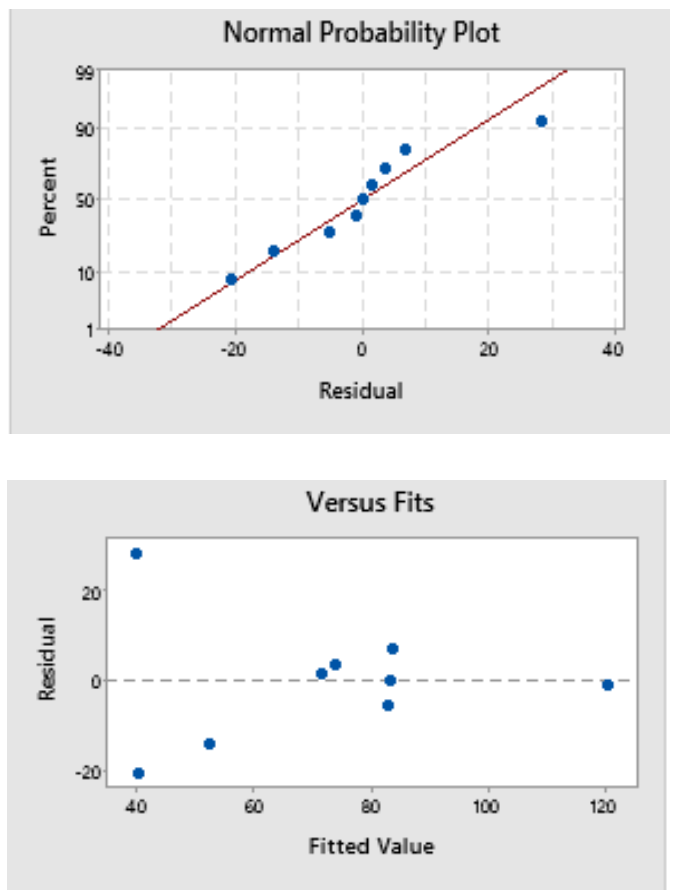

(b) Turbidity

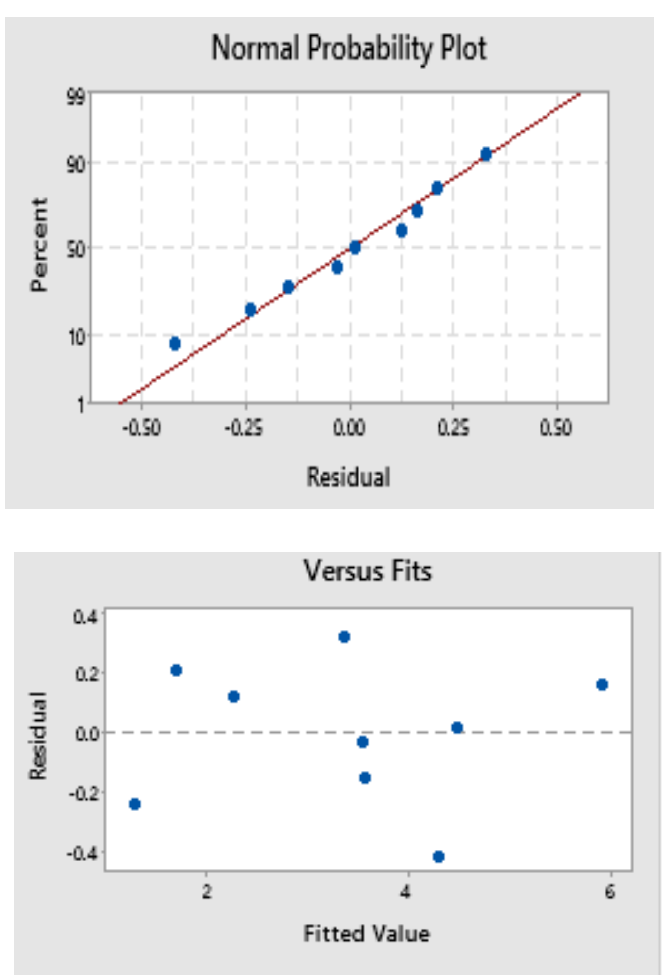

(c) Density 

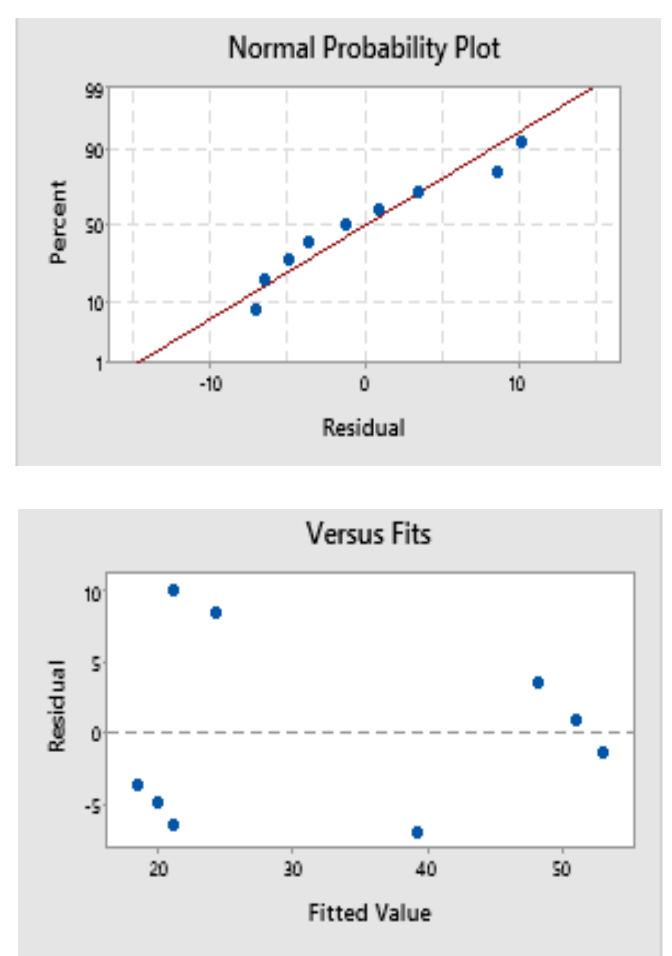

(d) Viscosity
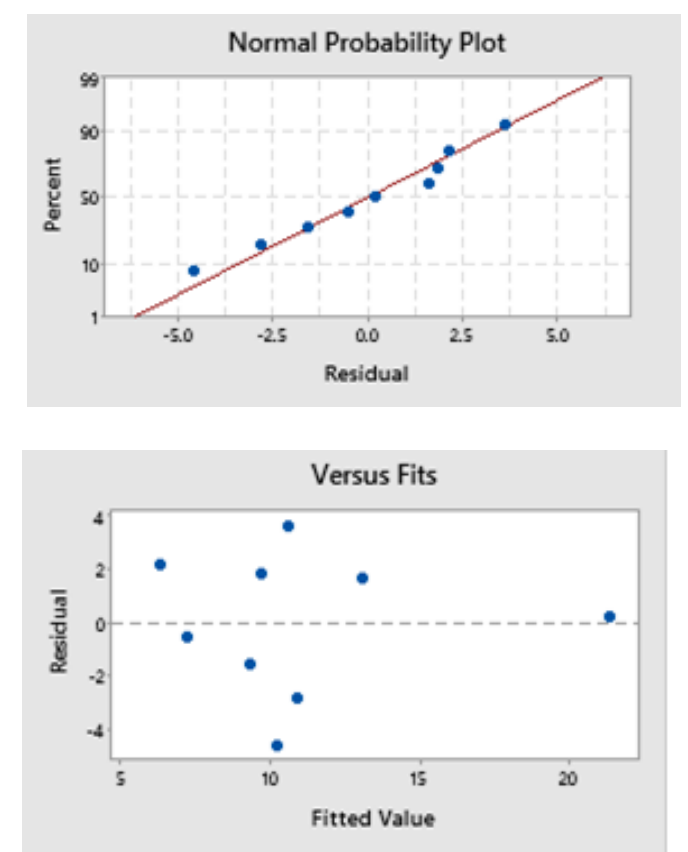

(e) High heating value (HHV).

Figure 2: Scatter diagram of: (a) Yield ( $\eta$ ); (b) turbidity (Turb); (c) density ( $\rho$ ); (d) viscosity $(\mu)$; and (e) high heating value (HHV).
5.3 Multi-response optimization

The combination of process variables were studied in examining the biodiesel production process by means of desirability package according to nine different criteria. From the results, it shows that the optimal process variables for various design requirements were found in an exceedingly relatively narrow range. Once the various biodiesel optimization scenarios were obtained, nine new experiments in keeping with the mix of process variables were prepared so as to work out the accuracy of the proposed methodology. Table 10 shows the values of various biodiesel outputs in step with the nine biodiesel optimization scenarios that were studied. These tables' shows that the experimentallyobtained values for the nine biodiesel optimization scenarios failed to differ significantly from those who application of the MRS methodology produced. The error that appears within the last two columns represents the MAE and RMSE that were normalized for every variable in each of the nine biodiesel optimization scenarios that were studied. However, the normalized MAE and RMSE within the last two rows correspond to the error in each of the outputs that were studied. as an example, when minimize the turbidity is taken into account to be an optimization variables for biodiesel production, the errors obtained are the tiniest (MAE $=0.02$ and RMSE = 0.02), but when minimizing the viscosity and density the error considered is that the largest $(\mathrm{MAE}=0.10$ and $\mathrm{RMSE}=$ 0.07). In contract, the most error obtained for every of the outputs are lower when predicting viscosity $(\mathrm{MAE}=0.01$ and $\mathrm{RMSE}=0.00)$ and greater when predicting turbidity $(\mathrm{MAE}=0.03$ and RMSE $=0.08$ ). 
Table 10: Experimental outputs according to the nine biodiesel optimization scenarios.

\begin{tabular}{|c|c|c|c|c|c|c|c|}
\hline \multicolumn{8}{|c|}{ Experimental Values Obtained } \\
\hline $\begin{array}{l}\text { Optimization } \\
\text { Scenarios }\end{array}$ & & Turb(NTU) & $\mathrm{P}(\mathrm{g} / \mathrm{mL})$ & $\mu(\mathrm{mm} / \mathrm{s})$ & $\mathrm{HHV}(\mathrm{MJ} / \mathrm{Kg})$ & MAE & RMSE \\
\hline $1^{\text {st }}$ Scenarios & 0.97 & 0.03 & 0.87 & 0.30 & 0.22 & 0.04 & 0.02 \\
\hline $2^{\text {nd }}$ Scenarios & 0.98 & 0.01 & 0.67 & 0.29 & 0.18 & 0.07 & 0.04 \\
\hline $3^{\text {rd }}$ Scenarios $C$ & 0.97 & 0.02 & 0.87 & 0.30 & 0.21 & 0.02 & 0.02 \\
\hline $4^{\text {th }}$ Scenarios 0 & 0.00 & 0.94 & 0.00 & 0.00 & 0.00 & 0.10 & 0.07 \\
\hline $5^{\text {th }}$ Scenari $\quad 0$ & 0.97 & 0.01 & 0.78 & 0.99 & 0.98 & 0.06 & 0.04 \\
\hline $6^{\text {th }}$ Scenarios 0 & 0.97 & 0.01 & 0.97 & 0.32 & 0.21 & 0.09 & 0.03 \\
\hline $7^{\text {th }}$ Scenarios $C$ & 0.96 & 0.00 & 0.87 & 0.34 & 0.21 & 0.02 & 0.04 \\
\hline $8^{\text {th }}$ Scenarios & 0.97 & 0.03 & 0.96 & 0.36 & 0.21 & 0.10 & 0.06 \\
\hline $9^{\text {th }}$ Scenarios 0 & 0.97 & 0.01 & 0.98 & 0.39 & 0.21 & 0.04 & 0.02 \\
\hline MAE & 0.03 & 0.03 & 0.01 & 0.01 & 0.01 & 0.09 & 0.03 \\
\hline RMSE & 0.07 & 0.08 & 0.07 & 0.00 & 0.03 & 0.34 & 0.12 \\
\hline
\end{tabular}

\section{Conclusions}

This work was investigated to analyze yield, turbidity, density, viscosity and HHV of biodiesel from some non-edible seeds oils. Response surface methodology supported the Box-Behnken design was employed to study the effect of the method variables on the biodiesel production from nonedible seeds oils. According to the ANOVA the results obtained demonstrated that, although non-edible seeds oil were different seeds, the molar ratio and dosage of catalyst were one among the foremost vital factors within the yield of biodiesel production.(see Table 4), whereas the HHV was the least factors. Additionally, temperature was one of the foremost important factors that increased turbidity (see Table 5), whereas for the HHV, the dosage of catalyst was the most significant factor (see Table 9). Finally, the dosage of catalyst was one in every of the foremost important factors within the biodiesel production. The optimal conditions for optimum yield were found to be: molar ratio of 6.25 , catalyst loading of $0.75 \mathrm{wt}$ \%, response time of $19.88 \mathrm{~min}$, reaction speed of $499.99 \mathrm{rpm}$, temperature of $24.50^{\circ} \mathrm{C}$, the most biodiesel yield under these conditions was $100 \%$. Also, the optimal condition for maximum heating value was found to be: molar ratio of 5.60, catalyst loading of $1.01 \mathrm{wt}$. \%, interval of $20 \mathrm{~min}$, reaction speed of $499.59 \mathrm{rpm}$, temperature of $35.50^{\circ} \mathrm{C}$. The utmost biodiesel yield under these conditions was $100 \%$. Biodiesel has become more attractive due to its economic and environmental benefits.

\section{Conflict of Interest}

The authors declare that there is no conflict of interest. 


\section{References}

C.B. Marina, L.L. Rubén, E.G. Rubén, S.G. Fátima, P. Eliseo P and G. Vergara (2017), An Improvement in Biodiesel Production from Waste Cooking Oil by Applying Thought Multi-Response Surface Methodology Using Desirability Functions, Energies, 10(1):1-20,

D.Y.C. Leung and Y. Guo (2006), Transesterification of neat and used frying oil: Optimization for biodiesel production. Fuel Processing Technology 87, 883-890.

G.E. Box, and K.B. Wilson (1951), On the experimental attainment of optimum conditions. Journal of Statistical Society. Ser. B (Methodological)

G.F. Silva, F.L Camargo and A.L. Ferreira (2011), Application of response surface methodology for optimization of biodiesel production by transesterification of soybean oil with ethanol. Fuel Process Technology. 92, 407-413.

H. Hamze, M. Akia and F. Yazdani (2015), Optimization of biodiesel production from the waste cooking oil using response surface methodology. Process Safe Environmental. Protection. 94, 1-10.

I. E Akubugwo, V. Chinyere and A.E. Ugbogu (2008), Comparative Studies on Oil from Some Common Plant Seeds in Nigeria. Pakistan Journal. of Nutrition 7(4): 570-573.

M. Kuhn, (2016), Desirability: Desirabiliy Function Optimization and Ranking. Available online: http://CRAN.Rproject. org/package $=$ desirability $\quad$ (accessed on 25 August 2016).

M. Mansourpoor and A. Shariati (2012), Optimization of biodiesel production from sunflower oil using response surface methodology. Chemical Engineering Process Technology. 3.

M. Tabatabaei, M. Aghbashlo, M. Dehhaghi, and H.K.S. Panahi (2019), Mollahosseini A., Hosseini M., Soufiyan M.M.Reactor technologies for biodiesel production and processing: A Review Progress in Energy and Combustion Science, 74.
M.W. Mumtaz, A. Adnan, F. Anwar, H. Mukhtar, M.A. Raza and F. Ahmad (2012), Response surface methodology: An emphatic tool for optimized biodiesel production using rice bran and sunflower oils. Energies, 5, 3307-3328.

N.S. El-Gendy, A.A. El-Gharabawy, S.S Amr and F.H. Ashour (2015), Response surface optimization of an alkaline transesterification of waste cooking oil. International Journal Chemistry of Technical Research. 8, 385-398.

R. Lostado, R. Escribano, M.A. Martínez and R. Múgica (2016b), Improvement in the design of welded joints of EN 235JR low carbon steel by multiple response surface methodology. Metals 6, 205-226.

R. Lostado, R.E. García and R.F. Martinez (2016a), Optimization of operating conditions for a double-row tapered roller bearing. Intenational Journal Mechanical Mater. Des. 12, 353-373.

R: The R Project for Statistical Computing. Available online: https://www.r-project.org/ (accessed on 25 July 2016)

T. Leevijit, G. Prateepchaikul, K. Maliwan, P. Mompiboon, S. Okaew and S. Eiadtron (2016), Production, properties, and utilization of degummed/esterified mixed crude palm oildiesel blends in an automotive engine without preheating", Fuel, 182: 509-516. 